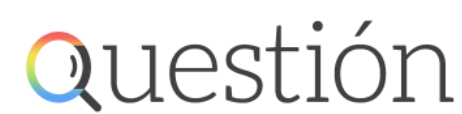

Periodismo / Comunicación ISSN 1669-6581
- Av. $44 \mathrm{~N}^{\circ} 676,1^{\circ}$ piso

CP 1900 - La Plata - Argentina

www.perio.unlp.edu.ar/question

\title{
Bolivia en medio de la pandemia, la corrupción y los Avengers
}

\section{Bolivia amid the pandemic, corruption and the Avengers}

Sergio Molina Monasterios

Boliviano y chileno. Doctor en estudios Americanos por la Universidad de Santiago de Chile; Magister en Ciencia Política y Licenciado en Comunicación Social por la Universidad Nacional de La Plata; Periodista de la Universidad Nacional de la Plata y de la Universidad de Chile. Especialista en comunicación política, ha participado en diversos grupos de investigación política y académica y es autor de libros y artículos sobre materias de su especialidad. Su último libro es "Cuadrar el círculo: las propuestas de solución al conflicto marítimo entre Chile y Bolivia". Ha sido responsable de las estrategias y campañas de comunicación de instituciones públicas, privadas y organismos internacionales. Actualmente trabaja en la Fundación Horizonte Ciudadano, institución creada por la ex Presidenta chilena, Michelle Bachelet.

\section{Palabras Clave}

Bolivia - Corrupción - Elecciones - Pandemia

\section{Keywords}

Bolivia - Corruption - Elections - Pandemic

En medio de la pandemia, una crisis económica que no da tregua y con un gobierno contra las cuerdas por la corrupción, Bolivia se encamina nuevamente a elecciones y a tener un gobierno legítimo elegido en las urnas que pueda enfrentar su difícil presente y futuro.

Esta semana el Tribunal Supremo Electoral, luego de diversas consultas políticas (algunas más confidenciales que otras), definió que el próximo 6 de septiembre se vuelva a las urnas.

Si bien los partidos políticos más importantes (el MAS de Evo Morales y Comunidad Ciudadana de Carlos Mesa), respaldan el acuerdo, otras fuerzas dirimentes como la del ultraderechista dirigente cívico "Macho" Camacho, no han demostrado simpatía con el nuevo cronograma; menos enfática, pero igual de escéptica, se encuentra la actual presidenta Jeanine Añez, quien observa con terror como el poder se le escurre por las manos.

En el campo internacional, el Secretario General de Naciones Unidas, Antonio Guterres, dijo en un comunicado que "acoge con beneplácito" la nueva fecha de las elecciones generales para el 
6 de septiembre. Esto se suma a otros organismos de Derechos Humanos que veían en la demora en la convocatoria a elecciones una intencionalidad que iba más allá de la sanitaria. Les elecciones estaban previstas para el 3 de mayo pasado, pero fueron suspendidas por la pandemia y el gobierno se negó a fijar un nuevo cronograma, frente a lo cual el TSE se hizo cargo del diálogo político y se convirtió en el actor más relevante y articulador en las últimas semanas y seguramente del futuro. El diálogo, hasta ahora, se encontraba en un punto muerte y la sociedad se polarizaba entre partidarios y opositores al MAS de forma alarmante.

El principal antecedente de este proceso son las elecciones del 20 de octubre de 2019, las cuales fueran anuladas luego de irregularidades denunciadas por la OEA, y de profundas movilizaciones sociales que terminaron en un golpe de Estado. Esas elecciones tenían como candidato favorito a Evo Morales por tercera vez consecutiva,

\section{Los antecedentes de la resolución}

La resolución electoral se produce cuando el gobierno provisional de Jeanine Añez está en su peor momento a escasos seis meses de haber asumido el mando, y luego de la renuncia de Evo Morales presionado por las Fuerzas Armadas y la policía.

Después de 14 años, el líder indígena había extenuado a la clase media boliviana (gran parte de la que ayudó a crear) con su afán reeleccionista y sus pulsiones autoritarias, y logró aunar en su contra a casi toda la población urbana, incluidas muchas organizaciones sociales que se movilizaron en unas jornadas confusas que terminaron con una treintena de muertos y con su renuncia; la cual, junto a la del vicepresidente Álvaro García Linera y de la presidenta del Senado, permitieron que Añez, una beniana de 53 años, una poco conocida senadora de oposición, se convirtiera en Presidenta interina.

Cuando asumió, la ola contrarrevolucionaria que había explotado el 2019 no parecía retroceder. Se trataba de un movimiento que comenzó democrático en su gestación pero que, al poco andar, desnudó el revanchismo y racismo del que estaba compuesto, cometiendo en poco tiempo los mismos errores que se le reclamaban a Morales; tratando de imponer una nueva hegemonía sin importar el costo. Si antaño el MAS lo hacía en nombre del pueblo y contra la oligarquía, hoy el oficialismo lo hacía por restaurar el orden conservador y neoliberal de los $90 \mathrm{~s}$.

Pero todo ello ocurrió antes del Covid-19 y sus secuelas que, entre otras cosas, dinamitó la pequeña y frágil estabilidad política que ocasionó la salida de Morales primero a México y 
después a la Argentina y que, por si fuera poco, agudizó la crisis del modelo productivo extractivista y de la economía rentista que acompañaron a Bolivia desde mediados del siglo XX.

\section{El colapso sanitario}

En pocas semanas, la pandemia puso de rodillas al gobierno y a la frágil institucionalidad boliviana y, como en el resto del planeta, desnudó las falencias estructurales de cada país, sus capacidades e incapacidades. En el caso boliviano, también la diferencia abismal que hay entre las elites aristocráticas blancas y el resto de los ciudadanos mestizos e indígenas.

El sistema de salud más ineficiente de América Latina, herencia perversa de los gobiernos neoliberales de antaño, pero también de Evo Morales y sus 14 años de políticas para la galería, dio todo lo que podía dar y, saturado en departamentos como Santa Cruz y Beni, colapsó sin remedio. Actualmente hay 10 mil infectados y los muertos se acercan a 400 , cifras oficiales conservadoras y que la gran mayoría de los especialistas pone en duda.

Frente a esa situación, los pocos bolivianos que pudieron hacerlo se refugiaron en una cuarentena feroz y sin tregua mientras los demás — la inmensa mayoría-, no tuvieron muchas más alternativas que rezar y abandonarse a su suerte... o aferrarse a lo mágico y sobrenatural: Añez y su séquito personal, hasta hace unos días, colgaban en sus cuellos un tarjeta-talismán que - según dicen - espanta el Coronavirus. Además, el gobierno autorizó el uso de un antiparasitario para perros que —también dicen-, puede ser útil para el tratamiento de la enfermedad.

El último capítulo de este drama fue la compra de respiradores médicos equivocados, duramente criticada por los especialistas, quienes denunciaron que son máquinas de emergencia que solo sirven para intervenciones cortas, no respiradores de terapia intensiva, destinados a estar conectados por largos periodos de tiempo.

La última ocurrencia del gobierno estuvo a cargo del ministro de Obras Públicas, Iván Arias, quien mostró a la prensa varios muñecos de los Avengers (la taquillera saga de Marvel Comics): Thanos el supervillano de varias de las últimas películas, representando el Coronavirus y, al frente, Iron Man y Hulk, en nombre de los valores positivos de los bolivianos. Lo que está claro es que la analogía fue comentada hasta en el último rincón de Bolivia y se recordará por muchos más años de los que Arias será ministro. 


\section{La tentación autoritaria}

La pandemia no es la única preocupación gubernamental. Recientemente se supo que dos vuelos de la Fuerza Aérea Boliviana fueron utilizados —en medio de la cuarentena-, para trasladar amigos de la mandataria con fines particulares. El hecho generó indignación y críticas, no solo por el uso indebido de bienes públicos, sino por las insostenibles justificaciones de Arturo Murillo, Ministro de Gobierno quien, en lugar de pedir disculpas, dijo que se trataban de "vuelos humanitarios". Murillo es la mano derecha de la Presidenta y se ha caracterizado por sus malas maneras, su discurso autoritario y, sobre todo, por amenazar y encarcelar opositores.

Lo curioso es que en uno de esos vuelos "humanitarios" viajó un amigo de la hija de la Presidenta para asistir a su fiesta de cumpleaños y, en el otro, el Ministro de la Presidencia y una modelo con la que, al parecer, mantiene una relación estrecha. Yerko Núñez, el ministro en cuestión, alegó que la jovencita tenía problemas de salud. Sin embargo, las fotos difundidas en Instagram la muestran feliz y rozagante en el avión oficial.

Todo ello mientras las pruebas de coronavirus de las decenas de contagiados que surgen en todas partes son enviadas por carretera, en buses destartalados y lentos, a alguna de las tres ciudades que cuentan con laboratorios para procesarlas.

A estos escándalos se suman las renuncias de la mayor parte de los flamantes gerentes de las empresas estatales (nacionalizadas por Morales en su momento), debido a distintas denuncias de corrupción e ineficiencia, lo que ha llevado a decir en broma a muchos bolivianos que pocas veces se hizo tanto en tan poco tiempo. Las redes sociales difuminan y fragilizan la política... pero también hacen que sea más difícil que la corrupción bananera pase desapercibida.

En estos días también se han tomado otras medidas igual de controvertidas que las sanitarias y las aeronáuticas en lo referido a la libertad de expresión, lo cual no ha sido característica solo de este gobierno sino también del anterior. En efecto, desde 2016, hubo al menos cinco intentos de regular medios y redes sociales con el fin de frenar la propagación de la "desinformación". El último caso fue un decreto supremo que imponía penas de cárcel a quienes "desinformaran" sobre el Covid-19, pero a los pocos días la Presidenta tuvo que arrepentirse ante la unanimidad de las críticas nacionales e internacionales. 


\section{Una historia repetida}

Añez, se presentó como la líder que iba a barrer con el aparato montado por el MAS durante 14 años y lo acusó reiteradamente de corrupción y nepotismo. Comenzó viajando en una línea aérea comercial porque decía que no quería repetir las prácticas de Morales que usaba sistemáticamente helicópteros y aviones oficiales para recorrer el país.

Sin embargo, meses después, se convenció de que el uso de aeronaves no era tan malo y no solo servían para ir a poblaciones alejadas y ser casi omnipresente como su antecesor; paralelamente, decidió que no solo sería la mujer que condujera la transición sino también candidata a la Presidencia del Estado Plurinacional. Su decisión desarmó las intenciones de Luis Fernando Camacho, el dirigente de la ultraderecha cruceña que encabezó las movilizaciones contra Morales y que había reconocido sin pudor alguno que su familia había tocado reiteradamente las puertas de los cuarteles para derrocarlo.

Pero los errores de principiante de Camacho, su ingenuidad política, el desgaste reciente de Añez y el Coronavirus, reabrieron las posibilidades del tercero en discordia, Carlos Mesa, a quien parecería no interesarle demasiado el triunfo, pero que continúa siendo el político menos exótico de los que se disputan los votos de esa bolsa variopinta que es la oposición fanática que existe en amplios sectores del país al retorno de Morales al poder.

Por su parte el MAS sigue sólido liderando las intenciones de voto, sobre todo ahora que puede decir con justeza que no fue la corrupción o el autoritarismo, sino el racismo más descarado y campante el que avivaba a la oposición cuando ellos eran gobierno.

EI MAS tiene de candidato a Luis Arce Catacora, ex ministro de Economía y artífice del crecimiento, redistribución y de la estabilidad macroeconómica que caracterizó a Bolivia en los últimos 14 años (con el imprescindible auxilio de la bonanza internacional que se vivió en ese mismo periodo y que ahora rueda por el despeñadero) y por David Choquehuanca, ex canciller de la República, con fuerte ascendencia sobre los movimientos campesinos e indígenas y siempre considerado un posible sucesor de Morales.

En ese escenario, gran parte de los bolivianos lo único que quieren es que la crisis se enfrente con firmeza y que no los mate o los empobrezca aún más. Pero para eso se necesitan autoridades representativas que tengan legitimidad para combatir al mismo tiempo el virus, la crisis económica y la pobreza extrema. El 6 de septiembre veremos si eso es posible... y si aún hay tiempo. 